\title{
ESCUCHANDO EL PASADO: HACIA UNA HISTORIA SOCIAL DE LA MÚSICA POPULAR
}

\author{
Juan Pablo González y Claudio Rolle \\ Programa de Estudios Histórico-Musicológicos, \\ Pontificia Universidad Católica de Chile
}

\section{Resumo}

Este artículo propone una sistematización de enfoques y metodologías de la investigación histórica en música popular, con énfasis en la historia social y la naturaleza y uso de las fuentes. Así mismo, revisa distintas estrategias de reconstrucción performativa de la música del pasado, y su utilización como fuente en la historia social de la música popular.

\section{Pallavras-Chave}

Historia Social • Música Popular • Performance Histórica

\section{Abstract}

This article proposes a systematization of approaches and methodologies for historical research in popular music, with an emphasis on the social history and on the nature and use of sources. Likewise, the article explores different strategies of performative reconstruction of the music of the past, and its use as a source in the social history of popular music.

\section{Keywords}

Social History • Popular Music • Historical Performance 
“¿Qué fabrica el historiador cuando ‘hace historia’? ¿En qué trabaja? ¿Qué produce?”, se pregunta Michel De Certeau, agregando: “¿Qué oficio es éste?” En estas precisas y punzantes preguntas radica parte esencial de la actividad de los historiadores y musicólogos, y también, uno de los ejes que atraviesa una historia social de la música. A través de ellas, se establece un rasgo esencial del oficio de la historia, cual es la presencia de mediaciones que permiten la creación de vínculos y relaciones entre el mundo del presente y el territorio del pasado. ${ }^{1}$

"Me interrogo sobre la relación enigmática que sostengo con la sociedad presente y con la muerte gracias a la mediación de unas actividades técnicas", señala De Certeau, sintetizando lo que le entrega el método histórico al historiador. ${ }^{2}$ Ya Jules Michelet había escrito, más de un siglo antes, en un sentido análogo, que "La historia acoge y renueva estas pasadas glorias; confiere nueva vida a estos muertos, los resucita. Su justicia asocia así a los que no fueron contemporáneos, otorga una reparación a varios que habían aparecido sólo un momento para desaparecer. Viven ahora con nosotros de modo que sentimos a sus padres y amigos: así se forma una familia, una ciudad común entre los vivos y los muertos". ${ }^{3}$

La historia, como disciplina, tiene precisas tareas que cumplir para con la sociedad que la cobija, entregándole memoria y rasgos de identidad; intentando explicar cómo hemos llegado a ser lo que somos, y ofreciendo pistas acerca de nuestras formas de ser y comportamientos presentes. En este sentido, se trata de una disciplina fundamentalmente humanista, pues se interesa por los valores esenciales y distintivos del ser humano radicado en el tiempo y en el espacio, considerando su existencia en relación con los demás. Es, asimismo, esencialmente social, en cuanto no puede tener existencia sin la colaboración de otros, sin la mediación de las fuentes que hacen posible el tránsito entre

\footnotetext{
${ }^{1}$ Este artículo se basa en la introducción de los autores a su libro Historia social de la música popular en Chile, 1890-1950. Santiago: Editorial Universidad Católica y Casa de Las Américas, 2005, y en la ponencia sobre Reconstrucción performativa de fuentes musicales presentada por Juan Pablo González en el VI Congreso IASPM-AL en Buenos Aires, 2005. ${ }^{2}$ DE CERTEAU, Michel. “La operación histórica”. In: PERUS, Françoise (comp.). Historia y Literatura. México: Instituto Mora. 1994, p. 31.

${ }^{3}$ SCHAMA, Simon. Ciudadanos. Crónica de la Revolución Francesa. Buenos Aires: Javier Vergara Ed., 1990.
} 
el presente y el pasado. El trabajo del historiador, aunque sea aparentemente solitario, es siempre colectivo, pues se basa en los testimonios de las múltiples voces y vivencias de los protagonistas y testigos del acontecer en el tiempo, con los que construye su relato histórico.

Los historiadores dependen, en importante medida, de lo que otros han querido registrar, conservar, memorizar y también de lo que las mujeres y los hombres del pasado han deseado olvidar, borrar, silenciar. Es parte del oficio del historiador trabajar con los silencios, con las palabras no dichas, con las palabras dichas y no registradas, con las palabras dichas y consideradas triviales, con los gestos, los ademanes y los sueños. ${ }^{4}$

En el caso de la historia de la música, los testigos nos dan cuenta de la dimensión sonora del pasado, pocas veces considerada en las aproximaciones de la historiografía a la vida de las sociedades pasadas. Vivimos inmersos en un universo sonoro que condiciona nuestra existencia y, sin embargo, no concedemos la atención necesaria al mundo de los sonidos organizados - música que nos rodea. Jacques Attali advierte que el saber occidental continúa, después de veinticinco siglos, tratando de ver el mundo, y que no ha comprendido que el mundo no se mira sino que se oye, "no se lee, se escucha”, señala. Esta advertencia es particularmente pertinente para el ámbito de los historiadores y su devoción por la cultura escrita.

Por otra parte, durante mucho tiempo se ha construido una historia atenta casi sólo a la razón, sin poner demasiado cuidado en las sensibilidades y en la sensorialidad. La vida de las sociedades del pasado en dimensiones como las de la producción artística, en los colores y sonidos del acontecer humano, se presenta como un territorio que invita a los historiadores a realizar un recorrido de descubrimiento bajo el sello del amor por la humanidad y sus creaciones. ${ }^{5} \mathrm{La}$ apasionada aseveración de Lucien Febvre se hace aquí muy elocuente y encuentra un territorio propicio al sostener que la historia puede hacerse y debe hacerse "con todo lo que siendo del hombre depende del hombre, sirve al hombre, expresa al hombre, significa la presencia, la actividad, los gustos y las formas de

\footnotetext{
${ }^{4}$ GONZÁLEZ, Juan Pablo; ROLLE, Claudio. "Música popular urbana como vehículo de la memoria”. In: GARCÉS, Mario et al compiladores. M emoria para un nuevo siglo. Santiago: LOM, 2000, p. 313.

${ }^{5}$ ATTALI, Jacques. Ruidos. Ensayo sobre la economía política de la música. Trad. Ana María Palos, México: Siglo XXI, 1995, p. 11.
} 
ser del hombre”. Se generan así ocasiones, oportunidades y desafíos para hacer historia que esté atenta a los sentidos y a una sensibilidad viva. ${ }^{6}$

Franco Fabbri nos recuerda que vivimos inmersos en el sonido, que estamos expuestos a más de tres horas diarias de música producida por altoparlantes. Se trata de músicas diversas, pero que nos llegan usando las mismas tecnologías y a través de los mismos medios. Para estudiar el "sonido en el que vivimos”, advierte Fabbri, debemos tener presente que las relaciones entre música y mass media son incomprensibles si no se considera la especificidad de las técnicas que permiten la difusión masiva de la música; que las relaciones entre música y tecnología adquieren gran parte de su sentido en relación al trasfondo económico y político de los medios; y que las relaciones entre tecnología, música y mass media no pueden ser entendidas prescindiendo de las exigencias estructurales y de las necesidades históricas de la comunicación musical. ${ }^{7}$

En los últimos decenios, los historiadores han descubierto las ricas posibilidades que ofrecen las fuentes musicales para la mejor comprensión de la historia y, en el caso de la música popular, se nos abre una atractiva ventana para conocer las formas de reaccionar de una sociedad frente a procesos y circunstancias históricas de cambios profundos y porfiadas continuidades. De este modo, los cambios políticos y económicos mundiales, los nuevos medios de comunicación, las trasformaciones en las prácticas musicales, y los cambios de esfera de influencia cultural, nos dan claves de interpretación de y desde un patrimonio musical que ahora se propone como objeto de estudio.

Convencidos de que la historia es una disciplina fragmentaria, conjetural, y propositiva, realizamos historia social de la música popular como un eslabón de una cadena que, esperamos, sea cada vez más fuerte y prolongada en el rescate de experiencias humanas, de memoria y de escucha hacia el pasado. La historia es una disciplina fragmentaria, en cuanto el conocimiento del pasado se hace posible a través de fragmentos, pedazos e impresiones muchas veces regidos por el azar y que los historiadores recogen y estudian buscando significados posibles. Es conjetural, pues a través del ejercicio de la conjetura - juicio basado en los indicios o señales que se observan -, se establecen líneas de

\footnotetext{
${ }^{6}$ FEBVRE, Lucien. Combates por la historia. Barcelona: Ariel, 1975, p. 232.

${ }^{7}$ FABBRI, F. II suono in cui viviamo. I ventare, produrre e diffondere musica. Milán: Feltrinelli, 1996, p. 5.
} 
interpretación y comprensión de fenómenos históricos. Es propositiva, en cuanto se trata de un ordenamiento de los datos fragmentarios que, después de un riguroso y razonado análisis conjetural, se presentan como propuesta de cómo pudo haber sido el misterioso país del pasado.

\section{Las historias de la música}

Enfrentados a la tarea de hacer una historia de la música popular, podemos asumir distintos enfoques historiográficos, todos válidos, por cierto, en especial al abordar un campo de estudios fuertemente interdisciplinario como es el de la música popular. Estos enfoques pueden ser, entre otros, estético, artístico, económico, tecnológico, biográfico o social.

La posibilidad de privilegiar la aproximación estética siempre está presente en una historia de la música, especialmente mediante las consideraciones que provienen de la musicología. Las presunciones estéticas se pueden hacer perceptibles de diversas maneras: al establecer la categoría de clásicos de la música popular, por ejemplo, cuyo repertorio puede tener mayor tratamiento en la investigación, estamos apoyándonos en juicios de valor más o menos compartidos. Lo mismo sucede con la selección, disposición y análisis de materias y géneros musicales, que pueden obedecer a criterios de carácter prioritariamente estético.

Un enfoque artístico en la historia de la música supone el énfasis, ya sea en la obra y sus circunstancias de creación, interpretación y recepción, o, en los procesos composicionales que la producen, considerando las variaciones que dichos procesos experimentan a lo largo del tiempo. De este modo, interesa la aparición, desaparición y rescate de lenguajes y estilos, y la influencia de individualidades y de contextos sociales en estas transformaciones. Debido a que en música popular la obra no está totalmente fijada en partitura, sino que se define como tal a través de su performance, el registro o reconstrucción sonora resulta vital para su análisis en cuanto a producto artístico, ahora definido no sólo por el compositor de la música y el autor de la letra, sino, en importante medida, por sus intérpretes. ${ }^{8}$ En efecto, las variaciones que los procesos creativos en música popular experimentan a lo largo del tiempo, deben

\footnotetext{
${ }^{8}$ Incluso, la obra también es definida por sus consumidores, que hoy hacen propia la oferta musical de un modo muy diferente que en otras épocas, dados los avances tecnológicos, que permiten un grado de reproducibilidad superior.
} 
ser abordados paralelamente, desde la perspectiva de la performance, a los que se suman el arreglo, las estrategias de producción y los avances tecnológicos.

El énfasis en la economía y el desarrollo tecnológico también resulta relevante a la hora de escribir una historia de la música popular, dada la importancia de los medios y de la industria cultural en la propia concepción de una música masiva, moderna y mediatizada, como es la música popular urbana. De hecho, uno de los temas insoslayables en los estudios de música popular, tiene que ver con el desarrollo tecnológico, con el crecimiento de los contactos y el intercambio internacional y con las transformaciones que los medios imponen a los usos y costumbres de los habitantes de una nación.

Sin embargo, a pesar del valor y necesidad de estos enfoques, ha sido nuestra intención enfatizar la historia social de la música popular, sin renunciar a la dimensión estética ni artística que posee la música - en las que también se expresa la sociedad que la contiene -, ni las bases económicas y tecnológicas de su desarrollo. Nos interesa descubrir cómo una sociedad recibió, seleccionó, transformó, hizo suya y preservó determinadas propuestas musicales; cuáles fueron sus condiciones de producción y consumo durante más de medio siglo y cómo se construyeron sus posibles sentidos. Nos interesa conocer, a través del sonido, a quienes compusieron, tocaron, bailaron y escucharon un repertorio que constituye un puente sensible entre nuestro tiempo y el pasado.

El enfoque histórico social, supone utilizar una serie de conceptos de manera explicita o implícita, como: rol social, clase, status, identidad, consumo y capital cultural, reciprocidad, poder, centro y periferia, mentalidad, ideología, género, comunicación y recepción, oralidad y escritura, hegemonía, y mito. Estos conceptos constituyen herramientas interpretativas necesarias para abordar la función social de la música, sus aspectos de producción y consumo, y su participación en la construcción de modos colectivos de percibir y reaccionar frente al mundo. En definitiva, la historia social nos permite captar, con relativa claridad, muchos factores dinámicos que están siempre presentes en la vida de las sociedades. Los ejes de continuidad y cambio, de innovación y conservación, de tránsito de esferas de influencia y de inserción cultural, aparecen con mayor claridad y hacen más comprensibles los desafíos que supone el estudio de la música popular en el tiempo.

En el ordenamiento temático y cronológico de una historia social de la música popular, intervienen factores de naturaleza social, productiva y musical, que, al ser articulados entre ellos, producen una base sólida sobre la cual hacer historia social. La música popular del siglo XX está muy vinculada al 
concepto de década, debido a que en música y cultura popular urbana, las décadas han marcado cambios y contrastes significativos a lo largo de todo el siglo. Otros hitos cronológicos, no menos importantes, lo constituyen los momentos de agitación social tanto internos como externos; y las guerras mundiales. Así mismo, la industria musical aporta sus propios hitos cronológicos y temáticos, ligados a la masificación de la cultura popular asistida por la invención técnica y la iniciativa empresarial. La música, a su vez, entrega los suyos, vinculados a la aparición, desaparición y rescate de géneros musicales y estilos interpretativos y a la carrera artística de los músicos significativos.

Desde el punto de vista temático, una historia social de la música popular latinoamericana de la primera mitad del sigo XX, puede articularse en torno a ejes como: el espacio privado y público; la industria musical; los géneros musicales y escénico-musicales; la masificación del folklore; la influencia extranjera; y el baile social. Este tratamiento temático se basa en la premisa de la existencia de vínculos entre la música popular practicada en una región con la historia social de ese período. De este modo, un texto referido a la primera mitad del siglo XX, puede organizarse considerando los fenómenos de modernización, persistencia del antiguo orden, democratización del consumo, y masificación social ocurridos en el mundo burgués, obrero, y mesocrático, en el espacio público y privado, y en las relaciones entre estos mundos y los espacios sociales. Sobre estas premisas histórico-sociales, se puede abordar la historia social de la música popular, considerando géneros, prácticas musicales y estilos compositivos e interpretativos; los músicos nacionales y extranjeros que produjeron este repertorio; la industria que posibilitó la producción y circulación de dicho repertorio; los lugares y ocasiones en que esta música fue practicada; el uso que le brindó el público; y sus procesos de significación y transformación cultural y artística.

Así mismo, en una historia social de la música popular, es necesario utilizar cierto grado de terminología y notación musical para referirnos a fenómenos rítmicos, melódicos, armónicos, estructurales, tímbricos, expresivos y performativos que caracterizan el repertorio abordado. Si bien no se trata de producir un texto que se dedique a estudiar el desarrollo del lenguaje y del estilo de la música popular, sino más bien sus modos de uso, formas de circulación y construcciones de significado, los géneros musicales deben ser caracterizados musical y coreográficamente, como así mismo se deben considerar algunos rasgos estilísticos de la producción musical de los compositores e intérpretes abordados. Un disco compacto que acompañe el texto, puede sustituir las 
descripciones y reducciones notacionales de la música, complementando la lectura con la audición - la razón con la sensación -, guiada por comentarios analíticos incluidos en el texto y en las notas a pie de página. Para ampliar este procedimiento, también se pueden entregar referencias a grabaciones disponibles en archivos públicos y en el mercado, que correspondan a versiones, reconstrucciones o remastertizaciones del repertorio abordado en la investigación.

Una historia social de la música popular corresponde a una formulación interpretativa que, fruto de años de investigación, tiene como rasgo característico el "proponer posibilidades de ordenamiento para los fragmentos que nos llegan del pasado, recurriendo a lo que los documentos nos dicen y a lo que no nos dicen, conjeturando sobre lo que pudo ser ese pasado que sólo conoceremos en una visión mediatizada y parcial, con mucho de ilusorio e incierto, fuertemente marcada por las emociones y los sentimientos, por las situaciones personales de tiempo y espacio"”. El tema a tratar es inmenso y variado, elusivo en ocasiones, engañoso en otras, pero, muy presente en la vida de la sociedad que la contiene. La intención es conocer un grupo humano determinado, recorriendo en el tiempo su práctica musical; el desarrollo de sus discursos y retóricas; y sus modos de decir y de callar, de sonar y de no hacerlo, pues los silencios de la historia suelen ser muy elocuentes. Cuando no tengamos registros de lo que podamos considerar como actividad musical, es legítimo probar vías para inferir información indirecta de los silencios de las fuentes, conjeturando sobre el sonido de un pasado enmudecido.

\section{Las fuentes de la música popular}

La figura de Asuraceturix, el bardo de la aldea de Asterix, creación de René Goscinny y Albert Uderzo, representa a cabalidad el drama del cómo no logramos aferrar testimonios del pasado. El arte del bardo de la aldea gala no es comprendido por sus compañeros, que no sólo no registran de ninguna forma su canto, sino que, la mayor parte de las veces, le impiden expresarse a través de la música y la poesía. Con ello, se cierra la posibilidad de la transmisión oral, la oportunidad para que algún personaje de sensibilidad divergente - y quizás a esa altura contestataria - recogiese su legado y lo reprodujese. Para nosotros, la música y poesía de Asuranceturix no existe a pesar de que sabemos por Goscinny

${ }^{9}$ Ver GONZÁLEZ; ROLLE. 0p. cit., 2000. 
y Uderzo que la creo e intentó infructuosamente comunicarla. El drama del bardo y su legado se ha repetido innumerables veces a lo largo de la historia.

De este modo, la música popular que puede ser historizada, es aquella que ha dejado registros e indicios, sean estos escritos, sonoros e iconográficos, evidentes o conjeturables, y que se conservan en la memoria de las personas. Es así como nos encontramos con un conjunto de fuentes de distinta naturaleza - impresas, grabadas y orales - que deben ser puestas a dialogar entre ellas, buscando generar un tejido polifónico para los ojos y oídos del historiador y del musicólogo. Los impresos incluyen fuentes primarias - literarias, musicales, e iconográficas -, y secundarias, que corresponden a una bibliografía formada por textos teóricos y de referencia, monografías, biografías, ensayos y novelas. Estos textos deben girar en torno a la historia, la sociedad, la cultura, y la música de un lugar en un período determinado y sus esferas de influencia.

La literatura de ficción, en particular la novela producida durante el período estudiado, entrega luces para captar la imagen de una época retratada indirectamente a través de sus tramas argumentales y descripciones de ambientes y personajes. De este modo, podemos obtener impresiones, matices y sensaciones que son difíciles de conseguir de fuentes más convencionales. Si bien se trata de contribuciones que iluminan de manera genérica e imprecisa, donde no puede distinguirse con seguridad la ficción de la observación directa de una realidad, resultan útiles justamente por su voluntad de retratar costumbres y atmósferas de manera verosímil y plausible.

En el uso de estas y otras fuentes podemos hacer lo que Robert Darnton ha llamado "historia con espíritu etnográfico", que define como el intento de explicar más cómo pensaba una época que lo que pensaba, y cómo construyó su mundo, le otorgó significados y le infundió emociones. Darnton explica que su forma de hacer historia "podría llamarse historia cultural, porque trata nuestra civilización de la misma manera como los antropólogos estudian las culturas extranjeras: es historia con espíritu etnográfico.” Añade más adelante, “donde el historiador de las ideas investiga la filiación del pensamiento formal de los filósofos, el historiador etnográfico estudia la manera como la gente común entiende el mundo". ${ }^{10}$ Así, pues, la naturaleza de las fuentes empleadas es va-

${ }^{10}$ DARNTON, Robert. La gran matanza de gatos y otros episodios en la historia cultural francesa. México: Fondo de Cultura Económica, 1987, p. 11. 
riada y resulta difícil establecer un patrón común para ellas. Sólo debemos señalar que no conviene descartar ningún tipo de registro documental o fuente que nos aproxime al mundo que estudiamos, no obstante las diferencias cualitativas y cuantitativas de algunas de ellas.

En la realización de una historia social de la música en Chile entre 1890 y 1950, nos fueron útiles una serie de fuentes primarias impresas formadas por periódicos y revistas publicadas principalmente en Chile; memorias, crónicas, discursos, carnés de baile y textos de interés institucional, comercial o técnico - anuarios, guías comerciales, boletines, catálogos, manuales, prospectos, programas, tratados, partituras y cancioneros - utilizados como fuente musical e histórica. A esto se agregan las fuentes iconográficas de época.

Desde que comenzó a desarrollarse una actividad musical pública, primero ligada a la escena y luego a la industria cultural, y fue adquiriendo importancia la prensa periódica, nos encontramos con referencias e informaciones musicales que surgen del registro de lo que a los habitantes del pasado les pareció digno y necesario de destacar. Editores musicales; constructores e importadores de instrumentos; promotores de conciertos, teatros y salones de baile; sellos discográficos; y almacenes y tiendas de música, necesitaban informar a sus consumidores de sus productos y estimular su demanda, publicando regularmente avisaje en la prensa escrita y en otros medios, como partituras, programas, catálogos, volantes y sobres de discos. Esta promoción musical de alcances masivos, no habría sido posible sin el acelerado crecimiento que experimentaba el avisaje en la sociedad occidental a comienzos del siglo XX, que encontraba en las fuentes impresas su principal medio difusor ${ }^{11}$.

La información proporcionada por la prensa latinoamericana durante la primera mitad del siglo XX, permite esbozar un mapa bastante completo del recorrido de la música popular y del baile social en la región, según las decisiones de sus propios protagonistas, expresadas en anuncios, reportajes y críticas de músicos y música ligada a la escena, al salón y más tarde a la industria mediática. Este discurso público sobre música popular, posee una dimensión tanto informativa como explicativa, pues no sólo se contribuía a la promoción

\footnotetext{
${ }^{11}$ Más sobre publicidad de música popular en SHEPHERD, John; HORN, David; LAING, Dave; OLIVER, Paul; WICKE, Peter (eds.). C ontinuum Encyclopedia of Popular M usic of the World. London: Continuum, 2003, p. 530-532.
} 
y al consumo musical, sino principalmente a construir su significado y a satisfacer la necesidad de normativa de la sociedad de la época.

De este modo, tanto los datos como las formas en que son presentados o sus narrativas -, constituyen el foco de atención al acercarse a las publicaciones periódicas de época. Del mismo modo, a través de la información de prensa no buscamos sólo conocer el mundo representado, sino cómo era representado y percibido por los habitantes del pasado. Así, a través de la iconografía y la música también queremos saber cómo se percibía el mundo. De esta forma, las fuentes visuales y sonoras nos hablan de sus contenidos y argumentos evidentes, pero también y de manera importante, de la visión - y audición - de quienes generaron y dieron forma a dichas fuentes ${ }^{12}$.

Para indagar en torno a la música popular y el baile del pasado, es indispensable el estudio de una variada iconografía que comprende desde antiguas viñetas ilustrativas de periódicos, hasta fotografías de vida social, pasando por el amplio territorio de la publicidad, las fotografías de crónica periodística y de las secciones de espectáculos, las ilustraciones de manuales y catálogos y las portadas de partituras. A eso se suma el cine de época y de reconstrucción histórica.

Las fotografías constituyen textos poseedores de distintos grados de elocuencia, que no sólo le otorgan un rostro al pasado, sino que nos hablan de ambientes, lugares, actitudes de músicos y público, uso de instrumentos, desarrollo tecnológico y estéticas de época. Es evidente una dimensión voluntaria e incluso autoral en algunas fotografías, como también lo es la dimensión accidental e involuntaria que deja gran cantidad de registros sobre la continuidad y el cambio de un mundo representado por el proceso químico de estas fuentes.

El uso de las fotografías contribuye a fortalecer la idea de proximidad con el mundo del pasado, produciendo lo que se ha llamado el "efecto realidad", si bien, como todas las fuentes, deben ser adecuadamente contextualizadas. Así mismo, las fuentes iconográficas, junto a los manuales de baile, nos permiten acceder a un territorio fundamental para la historia social de la música popular, pero, a la vez, menos tangible, como es el baile. Esta práctica social nos

\footnotetext{
${ }^{12}$ Esto se hace evidente en la adopción de determinadas convenciones y códigos que la fotografía del mundo del espectáculo teatral y musical utiliza con frecuencia, estableciendo, por ejemplo, determinada poses y gestos como característicos de la incipiente estrella, con consideraciones diferentes según el genero musical que se cultive. Ver BURKE, Peter. Visto y no visto. Barcelona: Crítica, 2001.
} 
entrega poderosas señales de los cambios de mentalidad y sensibilidad como expresión de instancias de continuidad y permanencia en ciertos casos, o de transformaciones significativas en las formas de percibir el mundo, los valores y la propia corporalidad.

A la fotografía se agrega el cine en la construcción de una historia social de la música popular, tanto películas de época como películas posteriores de reconstrucción histórica. Junto con la revisión directa de la filmografía, podemos acceder a sus argumentos, elencos artísticos, imágenes, críticas y publicidad a través de bibliografía y publicaciones periódicas. Las ediciones discográficas y de partitura nos permitieron escuchar su música.

$\mathrm{Al}$ igual que con la literatura de ficción, el efecto ilusorio de las imágenes en movimiento se revela como una fuente de grandes posibilidades. El cine nos otorga el privilegio de acceder al mundo cotidiano y extraordinario de los habitantes del pasado y de sus espacios públicos y privados, los que se entrecruzan en imágenes y sonidos, que, a través del filtro de un director, nos informan sobre prácticas, ocasiones y lugares para la música, el romance, la diversión, el baile y la socialización. Así mismo, el cine de reconstrucción histórica, nos ofrece un trabajo de investigación que apela a los sentidos, el cual, a la luz de nuestras propias indagaciones, es sometido a escrutinio, y siempre nos sorprende al reunir una infinidad de detalles que se han perdido en el tiempo.

Esta rica variedad de fuentes, sumada a las sonoras, que abordaremos en las páginas restantes, nos permite realizar el viaje a la sociedad del pasado, teniendo en cuenta las dificultades que este tipo de documentos proponen a sus intérpretes. La naturaleza múltiple del baile y de la canción, objetos centrales de una historia social de la música popular, que combinan texto, música, coreografía, arreglo, interpretación, grabación, y sus condiciones de circulación, conservación y consumo, genera diversos niveles de significación en una interpretación de la historia. Se producen así referencias cruzadas, formas de influencia e intercambio más o menos velados, y se deben inferir significados que en un tiempo eran evidentes y que, a muchos años de distancia, pueden resultar crípticos, como sucede, también, con la historia del humor. ${ }^{13}$

Las fuentes primarias constituyen un pasaporte hacia una cultura, entendiendo cultura como un sistema de significados, actitudes y valores compar-

\footnotetext{
${ }^{13}$ Ver PERONI, Marco. "Il nostro concerto”. In: Idem. La storia contemporánea tra musica leggera e canzone popolare. Florencia: La Nuova Italia, 2001; capítulo 1.
} 
tidos, junto a las formas simbólicas a través de las cuales éstos se expresan y traducen, que nos es próxima y lejana a la vez. Se trata de expresiones que nacieron en épocas con sensibilidades distintas a las nuestras y que no buscaron documentar un determinado momento para los investigadores del futuro, sino más bien comunicar, seducir y emocionar, convirtiéndose en testigos involuntarios de las vidas de mujeres y hombres de una nación a lo largo del tiempo. Justamente por su carácter involuntario, por su preocupación por lo inmediato y urgente, este tipo de fuentes resultan singularmente expresivas del sentir de una época, ofreciéndonos el privilegio de compartir emociones e invitándonos a imaginar sensiblemente un mundo que ya no existe, pero que ha dejado su indeleble huella en el presente.

\section{El sonido histórico}

La historia es una disciplina de interpretación, que se basa en la mediación de fuentes, en la adecuada comprensión de éstas y en la formulación de propuestas de ordenamiento de los datos que nos proporcionan, dando un sentido al acontecer. Este trabajo también se debe realizar con fuentes sonoras, con música, como testimonio del sentir de una época, de sus gustos y deseos, de sus tensiones y formas de expresión.

Desde hace largo tiempo, la historiografía no se conforma con las fuentes tradicionales para explorar los mundos que hemos perdido en el pasado, sino que busca todo tipo de recursos para aferrar esos esquivos escenarios de la memoria y la experiencia humana. La cultura material, las imágenes gráficas y los sonidos, han contribuido decisivamente a enriquecer la idea que podemos hacernos del pretérito y a tener una visión de la historia más sensible, menos exclusivamente intelectual y, en alguna forma, más sensorial, permitiéndonos sentir emociones y alegrías con quiénes ya no están, consolidando así una experiencia común que va mas allá de la vida de cada cual.

La existencia de fonotecas públicas, las iniciativas académicas de rescate de la producción fonográfica, y el afán de la propia industria discográfica de usufructuar de éxitos del pasado, ha permitido la recuperación, digitalización, conservación y circulación de material fonográfico antiguo, de gran valor para el estudio histórico de la música popular. Estas grabaciones permiten acceder al resultado sonoro de las prácticas performativas de época, constituidas por modos de canto, interpretación y arreglo desarrollados en el pasado. 
De todas maneras, conviene recordar que el disco, si bien es una fuente mucho más cercana al hecho sonoro en sí, sólo ha recogido una porción limitada de las prácticas musicales del pasado. Incluso, es muy probable que se hayan producido cierto blanqueamientos de prácticas emergentes de comienzos del siglo XX, como en el caso del tango y la milonga, por parte de la industria discográfica, para permitir su consumo por los sectores pudientes que compraban los discos. ${ }^{14}$

Nuestras raíces comunes están no sólo en el idioma sino también en otras tantas expresiones de este sistema de valores compartidos que llamamos cultura. La experiencia sensorial hace posible una relectura de la historia de otras sociedades, nos proporciona herramientas nuevas para comprender de mejor modo los logros y las limitaciones de esas sociedades y nos permite alcanzar, aunque sea parcialmente, uno de los desafíos permanentes en el oficio de la historia; esto es, compartir más directamente con quienes ya no están entre nosotros.

La música popular, en cuanto a fuente o dato del pasado, tiene la particularidad de ser una expresión que sólo existe en la práctica viva. Esta práctica supone performatividades, improvisaciones, escenificaciones, interacciones, y ambientes que no quedan completamente registrados en el tiempo. De este modo, si queremos acceder a la música popular como fuente en su real magnitud, debemos considerar tanto el dato como su narrativa, el qué junto con el cómo, pues ¿qué puede ser la música sino una narración de sí misma?

Para acceder a la música popular del pasado desde la perspectiva etnográfica propuesta por Robert Darnton, y para tratarla como fuente en toda su magnitud sensible, tendremos que reconstruirla como práctica performativa y escénica. Con ello, estaremos produciendo una triple acción, pues para reconstruir la fuente musical del pasado debemos establecer conjeturas informadas sobre sus datos ausentes, es decir, estaremos construyendo una interpretación de ella. Así mismo, como esta reconstrucción posee una dimensión artística, también estaremos comunicándonos mediante ella. Finalmente, la reconstrucción performática de la música popular del pasado es también una acción político-cultural, pues estamos contribuyendo al rescate patrimonial, a la construcción de memoria, y a la articulación de identidades y subjetividades colectivas.

\footnotetext{
${ }^{14}$ Conferencia presentada por AHARONIÁN, Coriún en el VI Congreso IASPM-AL, Buenos Aires, 2005.
} 
La práctica restauradora del pasado popular, se ha producido en diversos espacios sociales durante la segunda mitad del siglo XX, alcanzando cierta masividad desde la década de 1980. Al accionar de la industria y la academia, se suma la labor de músicos profesionales y aficionados; músicos de conservatorio y de bar; folkloristas y rockeros; y la del propio público consumidor. Cada uno de ellos con motivaciones distintas, pues cada época y sector social construye una interpretación del pasado que se articula en diálogo con las inquietudes y necesidades de su presente, con los temas nuevos y las conquistas de quienes, desde ese efímero momento que llamamos presente, buscan establecer un diálogo con la experiencia del pasado.

La reconstrucción de fuentes musicales anteriores al siglo XIX, que considera aspectos performativos como inherentes al repertorio reconstruido, es un fenómeno que se remonta a mediados del siglo XX. La valoración estética del sonido antiguo y de sus instrumentos y prácticas performativas asociadas, llevará a valorar la música antigua en sí misma y no como una mera etapa en el camino al reino de la tonalidad y de la música clásico-romántica.

Esta tendencia surge de la paulatina historización de la vida de conciertos desarrollada en Europa desde el revival de Bach de fines de la década de 1820, alimentada por la investigación musicológica temprana. Esta restauración de repertorio del pasado, encontró su máxima expresión a mediados del siglo XX con el rescate de la performance histórica. Ahora no sólo se rescataba el documento, sino que su forma de leerlo. Incluso se ha pretendido rescatar su forma de escucharlo, recreándose condiciones perceptivas pretéritas en base a variables acústicas, sonoras, lumínicas y escénicas. ${ }^{15}$

El rescate de la música popular del pasado, en cambio, empezó como una actividad de la industria discográfica, que comenzaba a valorar comercialmente sus registros viejos y mal conservados. Los avances tecnológicos en la grabación y reproducción del sonido, implicaban cambios del soporte sonoro, de modo que la primera gran remasterización discográfica; la generada por la aparición del disco de vinilo, y desarrollada desde los años cincuenta, constituyó una práctica regular de la industria para darle continuidad al catálogo de los grandes cantantes de las décadas anteriores, quienes mantenían así su condición de “artistas

\footnotetext{
${ }^{15}$ Sobre el problema de la performance histórica como una manifestación estética de la modernidad ver TARUSKIN, Richard. Text and Act. Essays on M usic and Performance. Oxford: Oxford University Press, 1995.
} 
de catálogo” incluso después de muertos, como en el caso de Carlos Gardel, por ejemplo. Lo particular surgió cuando esta remasterización comenzó a realizarse con artistas descontinuados, quienes empezaban a ser nuevamente comercializados bajo el concepto de "nostalgias musicales" o de "música del recuerdo”, en muchos casos, saltando del disco de 78 rpm al formato digital. Es aquí cuando la industria musical comienza a usufructuar del culto a la nostalgia, reinsertando y comercializando el sonido antiguo.

En efecto, el cambio de formato para actualizar el consumo, se apoya en el culto a la nostalgia desarrollado de la mano del historicismo de raigambre decimonónica, y su resignificación de productos culturales pretéritos. La nostalgia, corresponderá a un discurso de la memoria y a una forma de articular un sentido de pertenencia colectivo. De este modo, el estatus de "sonido auténtico" corresponde a una categoría otorgada por una escucha social: un sonido viejo, imperfecto y pasado de moda, ha comenzado a ser valorado en sí mismo, encontrándose en él frescura, autenticidad y verdad. Este fenómeno de rescate, que ha alcanzado su mayor énfasis a partir del revisionismo posmoderno, constituye una especie de remanso sonoro dentro de la gran complejidad y alto volumen del entorno musical actual, y apunta, junto a la world music, a una especie de "reinvención” de la verdad en tiempos de crisis de las verdades y bellezas absolutas.

Tanto el ámbito académico como el de la industria musical, comenzaron a dar pasos importantes en este sentido. Para ser justos, debemos reconocer que la consolidación de los estudios en música popular en la década de 1990 junto a la era digital, impulsaron el rescate y valoración de la música popular antigua. Si bien a mediados de los años sesenta el concepto de "nostalgias musicales” o de "oldies but goodies” (viejos pero buenos), ya suponía la aparición de la industria de la remasterización y de su radiodifusión en programas del recuerdo, es el formato digital el que impulsará su definitiva masificación cultural. Viviremos entonces "los años felices” de la industria del recuerdo. Con la valorización musicológica y social de estas fuentes, la música popular del pasado dejaba de ser anticuada y comenzaba a ser antigua.

La reconstrucción performativa de fuentes musicales debido a intereses académicos, participa de una tendencia social más amplia, que valora el retorno del sonido popular antiguo y de su performance. Las diversas motivaciones que han llevado al desarrollo de estas practicas de reconstrucción, pueden ser catalogadas de productivas, expresivas, estéticas, artísticas, patrimoniales, restauradoras, de consumo cultural y académicas. Si bien estas ocho moti- 
vaciones se cruzan entre sí, es posible determinar ciertos énfasis en cada una de ellas, como veremos a continuación.

\section{Motivaciones productivas}

Rescate de la estética de los años veinte y del charleston impulsado por Broadway y los profesores de baile en los años cincuenta. Con esto se renovaba la industria del music hall, y se continuaba con la vieja práctica de las academias de baile de reintroducir danzas del pasado. Este revival es extensible al jazz, con el renacimiento, a fines de los años cuarenta, del viejo estilo dixieland, como reacción ante las complejidades de la nueva práctica del cool jazz, gesto que puede ser entendido, también, como una motivación de tipo reactiva. En Chile, la comedia musical La Pérgola de las Flores (1960) de Francisco Flores del Campo e Isidora Aguirre, ambientada a fines de los años veinte, se constituyó, para el chileno, en la imagen sonora y visual por excelencia de los años locos, articulando el rescate de un pasado protector, en tiempos de la nueva locura desatada por el rock and roll.

\section{Motivaciones expresivas}

Canciones que adoptan formatos del pasado con intenciones expresivas, como “Amarraditos” (1963) de Belisario Pérez y Margarita Durán; “A la antigua” de Mario Clavell; y “Mazúrquica modérnica” (1966) de Violeta Parra. Las canciones de Belisario Pérez y de Mario Clavell, recurren al vals como el formato arcaico por excelencia desde el cual instalar su discurso restaurador. En ellas se expresa la complicidad de los amantes ante el anacronismo de su postura, quienes crean así un mundo a parte, que los identifica como pareja. En cambio, en "Mazúrquica modérnica”, Violeta Parra recurre a la mazurca, a la mandolina y a los versos esdrújulos como una forma de satirizar y expresar la extemporaneidad de una pregunta periodística que consideró inadecuada.

\section{Motivaciones estéticas}

Actividad de bandas de tributo y de covers bands, amparadas por el circuito de bares y pubs, que contratan bandas aficionadas. Algunas de ellas, entre las que abundan las que reproducen a Los Beatles, han profesionalizado su opción de covers de expresiones del pasado, llegando a niveles de virtuosismo en su práctica reproductiva. De este modo, Mario Olguín, líder del grupo chileno Beatlemanía (1989), afirma perfeccionar al propio John Lennon, corrigiendo 
algunas de las fallas en sus grabaciones. Así mismo, Beatlemanía celebró sus 15 años de vida en septiembre de 2004 tocando en vivo el LP Abbey Road (EMI, 1969) un disco netamente de estudio, que Los Beatles nunca tocaron en vivo. Es el culto al ídolo de la canción lo que genera esta práctica, que podemos catalogar de fanatismo performativo.

\section{Motivaciones artísticas}

Labor desarrollada desde mediados de los años setenta por distintos grupos que recrean tangos de la guardia vieja; canciones del cabaret alemán; o música de salon decimonónica, tanto europea como latinoamericana. Se destacan Walter Yonsky y el Cuarteto del Centenario (1975), quienes garbaron tangos y milongas del 900 con flauta y guitarras (Soy tremendo, Buenos Aires: Diapasón, 1995); Die Schönen der Nacht (1977), agrupación alemana de teatro musical, que recrea el cabaret expresionista alemán (Berlin im Licht, Freiburg: HHM\&M, 2001); y el grupo de cámara I Salonisti (1983) con sus montajes multimediales de música ligera y bailes europeos y norteamericanos de salón del siglo XIX (And the band played on, Londres: Decca, 1997). Incluso grupos de música antigua, como el ensamble madrileño AXIVIL Criollo, han hecho extensiva su labor al repertorio de salón decimonónico (En un salón de la Habana, Madrid: RTVE: 2000). También se destaca el rescate de compositores colombianos de comienzos del siglo XX realizado por el grupo de cámara colombiano Sincopando (Legado, Bogotá: Colcultura, 1998).

\section{Motivaciones patrimoniales}

El salón y el teatro constituyen la fuente de gran parte de la música folklórica latinoamericana tal como se practicaba a fines del siglo XIX. De este modo, la investigación y proyección folklórica, tarde o temprano se ha remitido a esas fuentes. En el caso de Chile, esto comenzó a ocurrir con Margot Loyola y su rescate a mediados de los años sesenta del cuplé o canción escénica (Salones y chinganas del 900, Santiago: RCA Victor, 1965), y continuó con el rescate de prácticas folklorizadas de salón por otros grupos chilenos de proyección folklórica. En esta tendencia, se sitúan los fenómenos de tradicionalismo, memorialismo, y folklorismo, que trabajan con la conciencia del rescate de la tradición, en este caso una tradición urbana revivida desde la práctica performativa. 


\section{Motivaciones restauradoras}

Restitución de la práctica del tango con guitarras de la Guardia Vieja y de repertorio de choro derivado del salón carioca, desarrollada por estudiantes de conservatorio a fines del siglo XX mediante el uso de arreglos y partituras (Principios do choro, Rio de Janeiro: Biscoito fino, 2002). Si bien no corresponde hablar de rescate, ya que se trata de géneros vivos; el hecho de arreglar, transcribir, y grabar tangos y choros como proyectos amparados por entidades públicas y académicas, y difundirlo mediante producciones discográficas independientes, se relaciona más con el concepto de restauración de una práctica performativa antigua, que con la continuidad de ella, que sin duda se ha modernizado y marcha por otros canales sociales y productivos. En este caso, tanto la continuidad histórica de un lenguaje musical como su restauración desde un ámbito sociomusical distinto, son prácticas que se superponen.

Aquí también cabe el caso de Buena Vista Social Club, pues se trata de la restauración de una práctica performativa en manos de sus propios músicos, pero que es fomentada desde un ámbito artístico-productivo externo. Su disco début de 1996, comercializado desde la world music, ha vendido más de 5 millones de copias en el mundo, redefiniendo este campo por introducir el factor de la historicidad performativa en él. Lo interesante es que en 1979 se había realizado una experiencia similar en Cuba con la grabación de los cinco LPs Las Estrellas de Areito, a cargo de un conglomerado de veteranos y jóvenes de la música popular cubana, que sin embargo no tuvo la repercusión internacional que alcanzó el proyecto Buena Vista, debido a que las condiciones para su recepción internacional aún no estaban dadas. ${ }^{16}$

Paralelamente, se han producido otras restauraciones performativas similares, siempre impulsadas desde músicos o productores de rock, como la realizada en Chile por Alvaro Enríquez con viejos músicos de bares y prostíbulos tocando cueca, vals y foxtrot en sitios de baile (La Yein Fonda, Santiago: Sony Music, 1996); y el proyecto del productor argentino Gustavo Santaolalla C afé de los maestros (Buenos Aires: Surco Records, 2005) quien, en un gesto inédito en su carrera, reunió a antiguos cantantes, compositores y músicos de tango, para producir una serie de conciertos, dos discos y un documental.

\footnotetext{
${ }^{16}$ Ver ACOSTA, Leonardo. "Popularidad, utopía y realidad del Buena Vista Social Club”. Enfoques, La Habana, 2-9, 2005.
} 


\section{Motivaciones de consumo cultural}

La extendida práctica actual del danzón en salones de baile de Ciudad de México; del baile aficionado en las gafieiras de Río de Janeiro; y del tango y la milonga en Buenos Aires, corresponde a un fenómeno de pervivencia de prácticas antiguas, respaldado por locales y profesores de baile, y por el propio público participante. Se trata de practicas sociomusicales que tuvieron su auge entre las décadas de 1930 y 1950, decayendo las gafieiras y el baile del tango con la llegada del rock and roll, y los salones de danzón por las restricciones impuestas a la vida nocturna en Ciudad de México. Sin embargo, estas practicas experimentaron un renacimiento en los años ochenta y noventa, rescatándose los espacios originales de encuentro social, con sus normas, protocolos, y formatos coreográficos y musicales (Acerina, la P rimer D anzonera de América, México: E\&M, 2000).

\section{Motivaciones académicas}

Junto a la práctica en medios universitarios de repertorios etnomusicológicos de otras latitudes, como una forma de entregarles bimusicalidad a los futuros investigadores, según el concepto de Mantle Hood, podemos agregar la practica del otro repertorio que está fuera del ámbito académico: la música $\operatorname{popular}^{17}$. Desde una perspectiva musicologica, interesa abordar la dimensión histórica tanto del repertorio oral como del mediatizado, y así lo estamos haciendo en el Instituto de Música de la Pontificia Universidad Católica de Chile con los montajes de los conciertos teatrales Del Salón al Cabaret (2002), Días de Radio en Chile (2003) y U na noche en el Goyescas (2007).

En este caso, nos anima un afán de investigación más que de formación bimusical, aunque hay objetivos científicos, artísticos y culturales que se entrelazan. Lo que hacemos es reconstruir performativamente la fuente musical, estudiando tanto el proceso como el resultado de dicha reconstrucción. En dicho estudio, se han abordado detalles como el uso de la voz y de sus formas de amplificación, problemas estilísticos de interpretación y de arreglo, la forma de dirigir, y la actitud corporal de cantantes y bailarines. Desde la perspectiva artística, constituye todo un desafío la manera de instalar esta reconstrucción

\footnotetext{
${ }^{17}$ Sobre los problemas de enseñanza y representación de repertorios etnomusicológicos ver SOLÍS, Ted (ed.). Performing ethnomusicology: teaching and representation in world music ensembles. Berkeley: University of California Press, 2004.
} 
performativa en la escena contemporánea, teniendo que resolver el modo de interesar y entretener al público del presente con un trabajo de investigación sobre música del pasado. Finalmente, desde el punto de vista patrimonial, no sólo estamos instalando en la sala de conciertos un repertorio popular pretérito, como ya ha ocurrido con los bailes del renacimiento y del barroco, sino que estamos colaborando a reconstruir y valorar nuestra propia memoria musical.

En estos montajes, se ha ofrecido una propuesta de interpretación de un período y de sus posibles escenarios sociales, recuperando prácticas performativas, de arreglo musical, y de baile, y reconstruyendo modos de comportamiento, gestualidad y vestuarios de época. Este ejercicio de reconstrucción musical, resulta especialmente iluminador en la realización de una historia social, sirviendo como una especie de laboratorio del que no se obtienen pruebas, sino posibilidades históricas, como propone Natalie Zemon Davis en torno a una experiencia similar en el campo de la historiografía y el cine. Esta reconstrucción abre una vía atractiva para los estudios histórico-musicológicos, al hacer posible la puesta a prueba de nuevos instrumentos críticos y plantear de manera innovadora y abierta al gran público dimensiones y problemas de la investigación académica.

Luego de participar en la filmación de El regreso de Martin Guerre, ambientada en Francia en el siglo XVI, la historiadora Natalie Zemon Davis publicó su obra homónima. "Escribir para los actores y no para los lectores me planteaba problemas nuevos sobre las motivaciones que podía tener la gente en el siglo XVI [...] Tenía la sensación de poseer un laboratorio histórico personal del que no obtenía pruebas, sino posibilidades históricas”. ${ }^{18}$

"La reconstrucción de mundos es una de las tareas más importantes del historiador. Éste emprende dicha tarea no por un extraño impulso que lo lleva a bucear en los archivos y a mirar papeles viejos, sino porque quiere conversar con los muertos. Interrogando los documentos y escuchando las respuestas puede sondear las almas de los que ya han pasado de este mundo y dar forma a las sociedades que ellos habitaron” señala Robert Darnton, quien añade que "si interrumpiésemos todo contacto con los mundos que hemos perdido, estaremos condenados

\footnotetext{
${ }^{18}$ Ver ZEMON DAVIS, Natalie. EI regreso de Martin Guerre. Barcelona: Antoni Bosch, 1984; XII.
} 
a vivir en un presente bidimensional, convertido en una jaula temporal y nuestro propio mundo se achataría”19. Estas consideraciones, nos acompañan en el esfuerzo de la investigación histórica y están presentes al momento de establecer las formas de trabajo con las fuentes siempre que busquemos orientar nuestro estudio hacia el ámbito de la historia social de la música popular.

\section{Palabras finales}

La historia se rehace e interpreta constantemente y día a día hacemos descubrimientos nuevos acerca de aspectos del acontecer a los que no habíamos prestado previamente atención. Cada generación - en rigor cada historiador y musicólogo - mira con su óptica particular documentos y fuentes, por lo cual la disciplina de la indagación e interpretación del pasado, es, en algún modo, inagotable. En este ejercicio (re)interpretativo, sólo sabemos con certeza que conocemos muy poco del territorio del pasado. Cada día nos damos cuenta de que nuestra interpretación se basa en aproximaciones razonadas y críticas, con voluntad indagadora, rigor y con ánimo de comprender los por qué de los acontecimientos humanos. Pero también sabemos que estamos lejos de las certezas absolutas. Por ello, puede suceder que existan interpretaciones dispares, incluso antagónicas, y sin embargo válidas de un mismo fenómeno. Así pues, lo que se presenta como historia social, es la propuesta interpretativa de quienes, con rigor y dedicación, han investigado ese pasado, estableciendo un vínculo con seres que ya no están y posibilitando una forma de intercambio que va más allá de las edades y la muerte.

Con la historia social de la música popular, se puede hacer un aporte a la valoración y recuperación de un patrimonio hasta ahora conservado con un halo de descuido o con tonos marginales, reestableciendo elementos importantes para la memoria común de la experiencia histórica del siglo XX. Debido a que la tarea del historiador es la de hacer comprensible al 0 tro, traduciendo otras sociedades a las lenguas de nuestro tiempo, la historia social debe realizar un esfuerzo para hacer comprensible y próximo el mundo ya ido al público contemporáneo. Para ello, contamos con fuentes que apelan al mundo de la razón y al mundo del sentido, con datos duros e impresiones pasajeras, que contribuyen, por igual, a estampar la huella que dejaron mujeres y hombres en el camino del pasado, que nosotros recorremos a tientas; un poco ciegos, un poco sordos.

\footnotetext{
${ }^{19}$ DARNTON, Robert. L'intell ettuale clandestino. Milán: Garzanti, 1990, p. 7.
} 


\section{Bibliografía}

ACOSTA, Leonardo. "Popularidad, utopía y realidad del Buena Vista Social Club”, Enfoques, La Habana, 2-9, 2005.

ATTALI, Jacques. Ruidos. Ensayo sobre la economía política de la música. Tard. Ana María Palos, México: Siglo XXI, 1995.

BURKE, Peter. Visto y no visto. Barcelona: Crítica, 2001.

DE CERTEAU, Michel. “La operación histórica”. In: PERUS, Françoise (comp.). Historia y Literatura. México: Instituto Mora, 1994.

DARNTON, Robert. La gran matanza de gatos y otros episodios en la historia cultural francesa. México: Fondo de Cultura Económica, 1987.

DARNTON, Robert. L'intell ettuale clandestino. Milán: Garzanti, 1990.

FABBRI, Franco. II suono in cui viviamo. I ventare, produrre e diffondere musica. Milán: Feltrinelli, 1996.

FEBVRE, Lucien. Combates por la historia. Barcelona: Ariel, 1975.

GONZÁLEZ, Juan Pablo. "Reconstrucción performativa de fuentes musicales para una historia social de la música popular”. In: VI Congreso de la Rama Latinoamericana del International Association for the Study of Popular M usic. Buenos Aires: Instituto Nacional de Musicología, 2005.

GONZÁLEZ, Juan Pablo; ROLLE, Claudio. "Música popular urbana como vehículo de la memoria”. In: GARCÉS, Mario et al compiladores. M emoria para un nuevo siglo. Santiago: LOM, 2000; p. 313-321.

GONZÁLEZ, Juan Pablo; ROLLE, Claudio. H istoria social de la música popular en Chile, 1890-1950. Santiago: Editorial Universidad Católica y Casa de Las Américas, 2005.

PERONI, Marco. “Il nostro concerto”. In: Idem. La storia contemporánea tra musica leggera e canzone popolare. Florencia: La Nuova Italia, 2001.

SCHAMA, Simon. Ciudadanos. Crónica de la Revolución Francesa. Buenos Aires: Javier Vergara Editor, 1990.

SHEPHERD, John; HORN, David; LAING, Dave; OLIVER, Paul; WICKE, Peter (eds.). Continuum Encyclopedia of Popular M usic of the World. London: Continuum, 2003.

SOLÍS, Ted (ed.). Performing ethnomusicology: teaching and representation in world music ensembles. Berkeley: University of California Press, 2004. 
TARUSKIN, Richard. Text and Act. Essays on M usic and Performance. Oxford: Oxford University Press, 1995.

ZEMON DAVIS, Natalie. El regreso de M artin G uerre. Barcelona:Antoni Bosch, 1984. 